\title{
Functional-oriented technological processes of electroerosive processing
}

\author{
S.Yu. Syanov \\ Bryansk State Technical University \\ Bryansk, Russian Federation \\ SERG620@mail.ru
}

\begin{abstract}
This article is a generalization of the results of theoretical studies of the effect of erosion control regimes on the operational properties complex profile parts.
\end{abstract}

The stages of the development of functionally oriented technological processes of electroerosive processing from the separation of the surfaces of parts and their service functions to the determination of the parameters of the process of electric erosion, which will provide not only the quality parameters of the surface layer, but also the required operational properties, are described.

The analysis showed that the fatigue strength is affected by the processing regimes and the coefficient after the erosion treatment. The index of wear resistance is determined both by the treatment modes and by the physical-mechanical properties of the billet materials.

Keywords - functionally-oriented technological process, electroerosion processing, performance indicators, quality of the surface layer.

\section{INTRODUCTION}

Electroerosive processing (EEP) is one of the most progressive and economically advantageous methods of processing materials in machine building. The process of forming the surfaces of parts in EEP is carried out by the most progressive method in comparison with the processes of mechanical processing of materials by cutting. EEP allows processing of both electrically conductive and non-electrically conductive materials irrespective of their physical and mechanical properties, the shape and location of the surfaces of the machined parts, which distinguishes it from machining by cutting, especially when processing hard-to-work materials.

Despite the positive technical, technological and economic indicators, the EEP has its own application fields and shortcomings due to its physical nature. The main disadvantage of EEP is high energy intensity in comparison with cutting machining in the manufacture of simple shape parts from structural materials under the same processing conditions (productivity and quality of the surface layer).

EEP is economically advantageous for processing products of complex spatial shape and hard-to-digest materials, and also in cases where surfaces are difficult to manufacture by other processing methods.

\author{
A.M.Papikyan \\ Bryansk State Technical University \\ Bryansk, Russian Federation \\ Papikan-alina@mail.ru
}

Thus, the EEP has a number of significant advantages that expand the field of practical application of this processing method in the manufacture of various engineering products

The processes taking place in the EEP have been studied in detail, the influence of technological processing regimes on the quality of the surface layer, the accuracy, wear of the tool electrode, and the productivity of the process have been revealed [1-5].

However, the destruction of mechanisms and machines (wear, fatigue, corrosion, etc.) begin with the working surfaces of parts, so the development of measures to improve their reliability based on the provision of specified, required or limiting operational properties is an actual problem. This problem is usually solved at the stage of design and technological preparation of products. A particularly important stage in the preparation of the manufacture of products is the development and implementation of the technological process of their manufacture. It is at this stage that the properties of the products are formed that are necessary to perform the required operational functions.

It can also be noted that the current technologies of EEP products provide the necessary performance indicators only for limited operating conditions. The solution of this problem is possible on the basis of application of functional-oriented technologies for the production of products by electroerosive methods [6;7].

\section{THE DEVELOPMENT OF A FUNCTIONALLY ORIENTED TECHNOLOGICAL PROCESS OF ELECTROEROSIVE PROCESSING}

The task, which is solved in the development of the functionally oriented technological process of the EEP, is to determine the optimal conditions for maintaining the EEP, ensuring the performance of the required operational functions and increasing the reliability of the product as a whole (Fig. 1).

The main stages of the development of functionallyoriented technological processes of EEP are the following:

1) analysis of basic structural elements and allocation of typical product surfaces;

2) determination of service functions of typical product surfaces; 
3) determination of the operational property or group of operational properties that ensure the performance of the service function surface of the product;;

4) definition of quality parameters of the surface layer providing an operational property or a group of operational properties [9];

5) consideration of the technological impact scheme, options and conditions for the implementation of technological operations of the EEP to ensure the necessary quality parameters of the surface layer.

Classification of typical surfaces of parts is carried out taking into account the general requirements for the development of the technological process. The technological process of billet machining is determined by the shape (configuration), the accuracy of processing and the quality of the machined surface, the material of the part, the dimensions, the annual output program and the overall production environment. Accordingly, the technological process of processing typical parts of the part must also take into account the above conditions (requirements, data, etc.). However, for a typical surface, the list of determining factors can be narrowed. The most significant parameters for a typical surface from the point of view of choosing the route of processing are the shape (shape) of the surface, the accuracy and quality of the surface, the type of the material of the work piece.

The dimensions of the part significantly affect the nature of the equipment and, to a lesser extent, the processing route.

Therefore, all the surfaces available on the parts can be divided into the following typical types:

1) outer cylindrical - smooth and stepped;

2) external conical;

3) internal cylindrical (holes) - smooth and stepped, through and deaf;

4) internal conical;

5) flat (including face and intermittent);

6) shaped;

7) threaded;

8) slotted;

9) teeth (of different profiles)

The type of a typical surface has a major influence on the EEP methods used, which are divided into the following varieties:

1) electroerosion interval;

2) electroerosive volumetric copying;

3) electroerosive excision;

4) electroerosion stitching;

5) electroerosive grinding;

6) electroerosive debugging;

7) electro-erosion hardening;

8) electroerosive alloying.

Having separated a product into typical surfaces, it is necessary to define their service functions.

Service functions of the parts surfaces are used by technologists to design the technological process of machining.

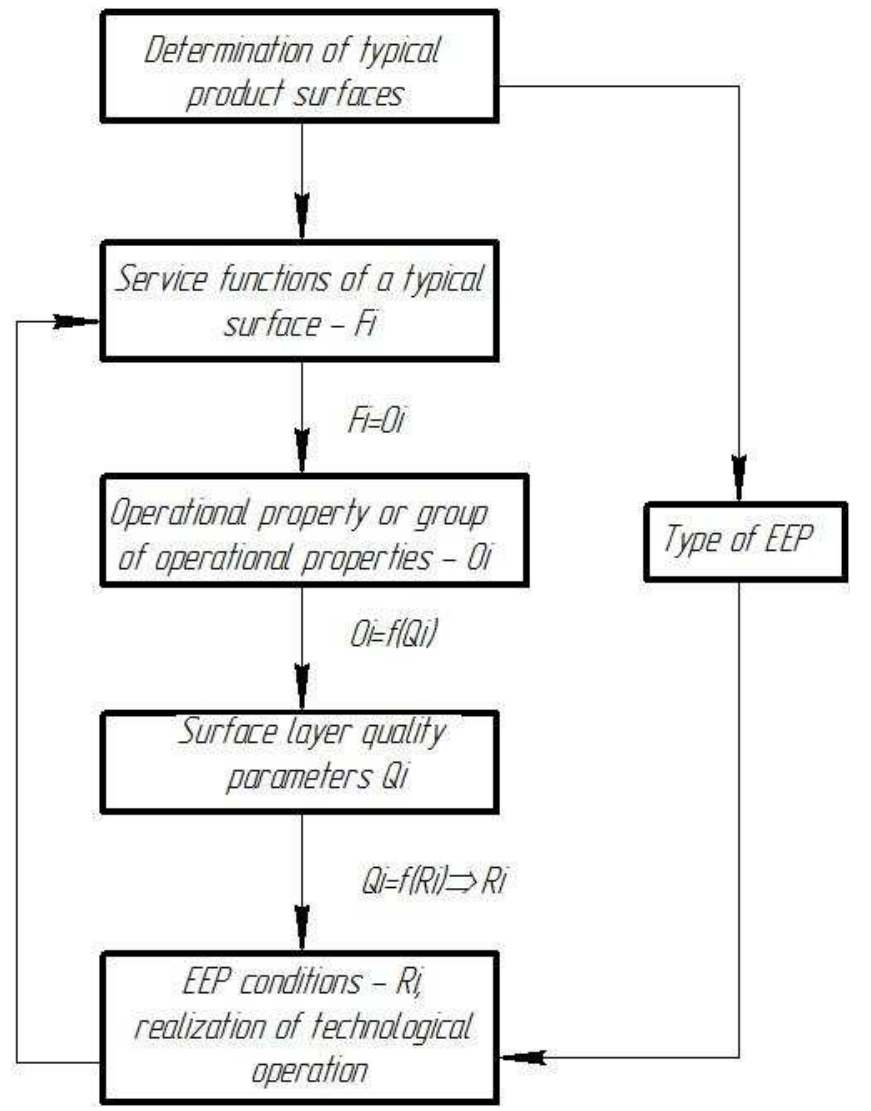

Fig. 1. Stages of the development of a functionally oriented technological process of electroerosive processing

Any product is intended to perform the appropriate service purpose through its surfaces. Consequently, each surface of the product is designed to perform a specific service function. The classification of product surfaces on the basis of service function is shown in Fig. 2.

Free surface (FS) are not mated with the surfaces of other parts. All free surfaces are binder, that is, they serve to unite all the executive surfaces into a single space "body-detail" and give the details the desired shapes, sizes, manufacturability, strength, aesthetics.

Executive surfaces (ESs) are surfaces by means of which the machine or its individual mechanisms fulfill their official function. The execution surfaces are subdivided into technological and design surfaces.

Technological surfaces (TS), are designed for technological purposes and do not significantly affect either the service purpose or the shape of the part. These include:

- separating TS (for example: technological grooves); technological goal (function) - the separation of surfaces with different accuracy during processing;

- basic TS (for example: center holes, technological grooves and holes, technological planes); technological purpose (function) - basing during processing, that is, contact with the base surfaces of the devices. 
Design surfaces (DS) - surfaces by means of which the machine or its individual mechanisms fulfill their service purpose; contact with the surfaces of other parts or with the working medium. Design surfaces are divided into working and basing.

Work surfaces (WS) are involved in the implementation of a particular working process of the machine.

The surfaces or the combinations of surfaces that replace them, relative to which the position of the other surfaces of the part are determined, is usually called basing surfaces or bases. The bases are characterized by a certain mutual arrangement, which forms a set of bases.

After determining the service functions $\mathrm{Fi}$ of the surfaces of products, it is necessary to determine the operational properties of $\mathrm{Oi}$ (wear resistance, fatigue strength, contact stiffness, corrosion resistance, etc.) that will ensure the performance of the required operational function.

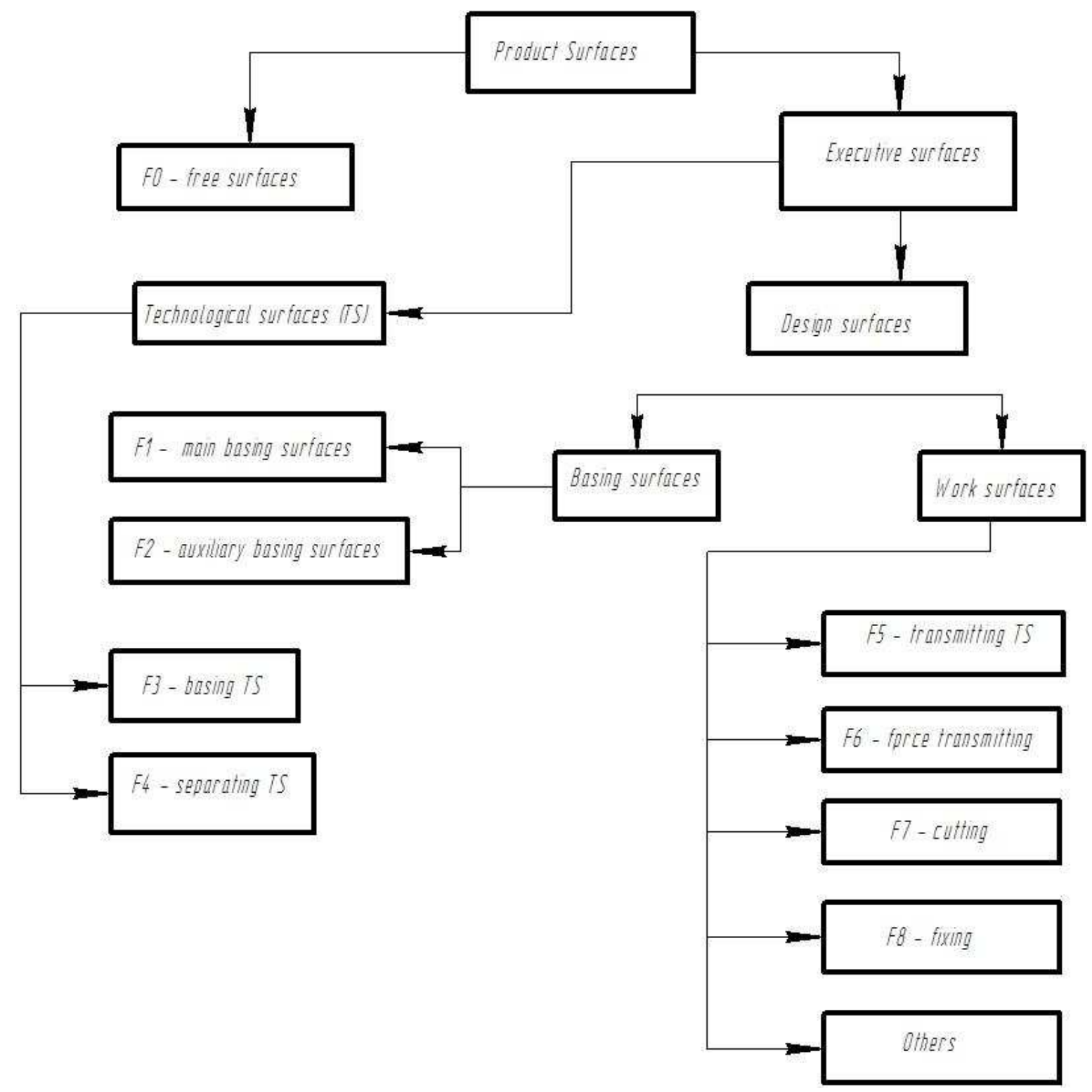

Fig. 2. Classification of the functions of product surfaces

Knowing the operational properties $\mathrm{Oi}$ and the functional interrelationships of these operational properties with the technological parameters, namely the quality of the surface layer $\left(\mathrm{O}_{\mathrm{i}}=\mathrm{f}\left(\mathrm{Q}_{\mathrm{i}}\right)\right)[10]$, it is possible to determine the optimal quality parameters of the surface layer $Q_{i}$ necessary to provide the required operational function of the surface $F_{i}$.

Using the obtained quality parameters of the surface layer Qi, the physics of the EEP process and the functional interrelation of the quality parameters of the surface layer with 
the conditions of conducting $\operatorname{EEP}\left(\mathrm{Q}_{\mathrm{i}}=\mathrm{f}\left(\mathrm{R}_{\mathrm{i}}\right)\right)[1-5]$, determine the necessary technological impacts $\mathrm{Ri}$ (electrode tool material, dielectric fluid properties, technological current, technological voltage, duration and duty cycle of the pulse, etc.) to ensure the required operational function of the product surface $F_{i}$.

\section{OBTAINING THE THEORETICAL DEPENDENCES OF FATIGUE STRENGTH AND WEAR RESISTANCE WITH THE MODES OF ELECTROEROSION MACHINING}

Fatigue strength is the property of the material not to destroy over time under the influence of changing workloads. Destruction occurs due to the appearance of microcracks, their accumulation, then merging into one macro-destruction. In the electroerosion treatment of complex profiles in the surface layer, residual stresses are formed, which leads to the appearance of microcracks. To solve this problem, it is necessary to provide such modes of electroerosion processing, which will not worsen the fatigue strength parameters.

The fatigue resistance is characterized by the stress concentration coefficient, which is calculated by the formula [7]:

$$
\alpha_{\sigma}=1+\frac{200}{t_{m} s_{m}}[2 \gamma R \max (R \max -R p)]^{0,5}
$$

where $R \max , R p, \mathrm{~S}_{\mathrm{m}}$ - roughness parameter, $\mathrm{t}_{\mathrm{m}}-$ relative reference length of the profile at the midline level, $\gamma_{-}$ coefficient of after electroerosion treatment, which must be determined as a result of experimental studies.

In turn, the parameters of roughness in the electroerosion processing can be calculated from the theoretical relationships [8]:

$$
\begin{array}{r}
\operatorname{Rmax}=\sqrt[3]{\frac{(2 \cdot \beta-1) \cdot \mathrm{I} \cdot \mathrm{U} \cdot \eta \cdot \tau}{(4 \cdot \beta+1) \cdot \mathrm{c} \cdot \rho \cdot \mathrm{Tme}}} \\
\mathrm{Rz}=0,84 \cdot \sqrt[3]{\frac{(2 \cdot \beta-1) \cdot \mathrm{I} \cdot \mathrm{U} \cdot \eta \cdot \tau}{(4 \cdot \beta+1) \cdot \mathrm{c} \cdot \rho \cdot \mathrm{Tme}}} \\
\mathrm{Sm}=4,5 \cdot \mathrm{Rz} \\
\mathrm{tm}=0,49 \cdot \mathrm{p}^{1,02}
\end{array}
$$

where $\beta$ - overlap factor of the wells, I - amperage, U voltage applied to the electrodes, $\eta$ - coefficient of useful energy of pulse, $\tau$ - pulse duration, $c-$ specific heat of material, $\rho$ - material density, Tme - melting point of material, $\mathrm{p}-$ level of section $(50 \%)$.

Substituting equations (2-6) into equation (1), we obtain:

$$
\alpha_{\sigma}=1+\frac{1,86 \gamma^{0,5}}{\sqrt[6]{\frac{(2 \cdot \beta-1) \cdot I \cdot U \cdot \eta \cdot \tau}{(4 \cdot \beta+1) \cdot c \cdot \rho \cdot T m e}}} .
$$

Thus, it can be concluded that the fatigue strength depends on the strength of the current, the voltage applied to the electrodes and the duration of the pulses.

Let us consider the second operational indicator - friction and wear.

Wear resistance is an operational property that determines the ability of the surface layers of parts to resist fracture during friction-sliding, friction-rolling, and also with microdisplacements caused by vibration. Friction and wear of parts are largely determined by the shape and height of the roughness, and by the direction of the processing strokes.

To evaluate the quality of friction surfaces, a parameter characterizing the equilibrium state of friction surfaces is proposed [7]:

$$
\mathrm{C}_{\mathrm{x}}=\frac{(\operatorname{RaWzHmax})^{1 / 6}}{\mathrm{t}_{\mathrm{m}}{ }^{3 / 2} \mathrm{~S}_{\mathrm{m}}{ }^{1 / 2} \mathrm{u}_{\mathrm{cW}}^{2 / 3} \lambda}
$$

where $\mathrm{H}_{\max }$ - surface macro deviations $\mathrm{W}_{\mathrm{z}}$ - surface waviness, $R_{a}, S_{m}$ - surface roughness parameter, $t_{m}$ - relative reference length of the profile at the midline level, $\mathrm{u}_{\mathrm{cw}}$ - surface layer degree of cold hardening, $\lambda$ - coefficient that takes into account the effect of surface residual stresses of the second kind on wear.

Surface waviness can be calculated using the theoretical relationship [8]:

$$
\mathrm{Wz}=0,5 \cdot \sqrt[3]{\frac{\mathrm{I} \cdot \tau \cdot \eta}{\mathrm{c} \cdot \rho \cdot \mathrm{T}}} \cdot\left(\sqrt[3]{\mathrm{U}_{\max }}-\sqrt[3]{\mathrm{U}_{\min }}\right)
$$

where I - amperage, $\eta$ - coefficient of useful pulse energy, $\tau$ - duration of pulses, $c$ - material specific heat, $\rho$ - material density, $\mathrm{T}-$ material melting point, $\mathrm{U}_{\max }-$ maximum stress during machining, $\mathrm{U}_{\min }-$ minimum stress during machining.

The degree of cold hardening of the surface layer is determined by the formula [9]:

$$
U_{H}=\frac{H_{h}-H_{s}}{H_{h}}
$$

where $\mathrm{H}_{\mathrm{h}}$ - cold-hardened layer microhardness, $\mathrm{H}_{\mathrm{s}}$ - starting material microhardness.

In its turn, the microhardness of the starting material in the electroerosion processing is determined by the formula [8]:

$$
h_{\mu}=10^{-3} \cdot \frac{A_{p}^{0,234} \cdot \Pi_{t}^{0,409}}{\Pi_{d}^{0,236}}
$$


where $A_{p}-$ pulse energy, $\Pi_{d}-$ Palatnik phase transformation coefficient of the part material, $\mathrm{P}_{\mathrm{t}}-$ Palatnik phase transformation coefficient of the tool material

The coefficient that takes into account the effect of surface residual stresses of the second kind on wear is determined by the formula [7]:

$$
\begin{aligned}
& \begin{array}{c}
\lambda=\left(\frac{\delta_{t e}-\delta^{\prime \prime} r e}{\delta_{a m}}\right)^{t} \quad(12) \\
C=\frac{\left[\sqrt[3]{\frac{I \cdot \tau \cdot \eta}{c \cdot \rho \cdot T}} \cdot\left(\sqrt[3]{U_{\max }}-\sqrt[3]{U_{\min }}\right) \cdot H_{\max }\right]^{1 / 6}}{0,0005 \cdot\left(\frac{(2 \cdot \beta-1) \cdot I \cdot U \cdot \eta \cdot \tau}{(4 \cdot \beta+1) \cdot c \cdot \rho \cdot T m e}\right)^{1 / 6} \cdot\left(\frac{\left(10^{-3} \cdot \frac{A_{p}^{0,234} \cdot \Pi_{t}^{0,409}}{\Pi_{d}^{0,236}}\right)-H_{h}}{\left(10^{-3} \cdot \frac{A_{p}^{0,234} \cdot \Pi_{t}^{0,409}}{\Pi_{d}^{0,236}}\right)}\right)^{2 / 3} \cdot\left(\frac{\delta_{t e}-\delta^{\prime \prime r e}}{\delta_{a m}}\right)^{t}}
\end{array} \\
& \begin{array}{c}
\lambda=\left(\frac{\delta_{t e}-\delta^{\prime \prime} r e}{\delta_{a m}}\right)^{t} \quad(12) \\
C=\frac{\left[\sqrt[3]{\frac{I \cdot \tau \cdot \eta}{c \cdot \rho \cdot T}} \cdot\left(\sqrt[3]{U_{\max }}-\sqrt[3]{U_{\min }}\right) \cdot H_{\max }\right]^{1 / 6}}{0,0005 \cdot\left(\frac{(2 \cdot \beta-1) \cdot I \cdot U \cdot \eta \cdot \tau}{(4 \cdot \beta+1) \cdot c \cdot \rho \cdot T m e}\right)^{1 / 6} \cdot\left(\frac{\left(10^{-3} \cdot \frac{A_{p}^{0,234} \cdot \Pi_{t}^{0,409}}{\Pi_{d}^{0,236}}\right)-H_{h}}{\left(10^{-3} \cdot \frac{A_{p}^{0,234} \cdot \Pi_{t}^{0,409}}{\Pi_{d}^{0,236}}\right)}\right)^{2 / 3} \cdot\left(\frac{\delta_{t e}-\delta^{\prime \prime r e}}{\delta_{a m}}\right)^{t}}
\end{array}
\end{aligned}
$$

where $\delta_{t e}-$ temporary fracture resistance, $\delta_{a m}-$ the effective value of the amplitude stress on the friction surface, $t$ - the parameter of frictional fatigue at elastic contact. obtain:

Substituting equations (2-6), (9-12) into equation (8), we
Thus, it can be concluded that the wear resistance depends on the modes of electroerosion processing.

\section{CONCLUSIONS}

The article describes a general approach to the development of functionally oriented technological processes of EEP based on a whole set of new principles for designing technological processes. To implement the functionally oriented EEP technologies, a general methodology and methodology for their implementation are presented. In the course of the theoretical studies, functional dependences of performance indicators (fatigue strength and wear resistance) on the conditions of electroerosion treatment were obtained. Fatigue strength depends on the strength of the amperage, the voltage applied to the electrodes and the duration of the pulses. Wear resistance also depends on the treatment modes and on the physical and mechanical properties of the workpiece materials.

Functionally oriented EEP technologies significantly increase the technical and economic performance of products and ensure the realization of their full potential. Also opportunities are created to ensure equal durability and quality of operation of all elements of the product. At the same time, labor costs for manufacturing products and their prime costs are significantly reduced.

\section{References}

[1] E.A. Sychev, A.S. Tarapanov, "Forecasting of surface roughness in electroerosion machining of parts of complex configuration", News of the Tula State University, Technical science, vol. 8, pp. 122-127, 2013.

[2] R.V. Lesnikov, T.R. Ablyaz, "Theoretical analysis of the influence of the parameters of electroerosion processing on the magnitude of the spark gap", Modern problems of science and education, vol. 2, p. 176, 2015.

[3] V.G. Kozlov, V.S. Volkov, "Modern methods of metal processing. Electroerosion treatment", Youth vector of development of agrarian science, pp. 180-184, 2015.

[4] M.Yu. Sarilov, M.A. Pokotilo, "Selection of quality management parameters for the electro-erosion treatment of parts surfaces", Automation. Modern technologies, vol. 4, pp. 3-9, 2009.

[5] A.F. Bretskih, V.I. Sysun, "Electroerosive treatment", Scientific notes of Petrozavodsk State University, vol. 2, pp. 78-82, 2010.

[6] A.N. Mikhailov, "General features of functionally-oriented technologies and principles of orientation of their technological influences and product properties", Mechanical Engineering and the Technosphere of the 21st Century, vol. 2, pp. 38 - 52, 2007 [Mechanical Engineering and the Technosphere of the 21 st Century].

[7] A.N. Mikhailov, "Functionally-oriented technologies", Mechanical Engineering and the Technosphere of the 21st Century, vol. 2, pp. $290-$ 314, 2008 [Mechanical Engineering and the Technosphere of the 21st Century].

[8] S.Yu. Syanov, "Theoretical determination of surface layer quality characteristics of workpieces, tool electrode wear and efficiency of spark eroding", In the collection: Proceedings of 2015 International Conference on Mechanical Engineering, Automation and Control Systems, pp. 1-4, 2015 [Proceedings of 2015 International Conference on Mechanical Engineering, Automation and Control Systems].

[9] M.M. Khrushchov, Friction, wear and microhardness of materials: Selected works (on the occasion of the 120th anniversary of his birth (Moscow: KRASAND) 2012, p. 512.

[10] A.G. Suslov, Scientific foundations of engineering technology, Moscow: Mechanical Engineering, 2002, p. 684. 